\title{
Factors influencing emergency medical competencies of health centers and fire stations in areas that are vulnerable to earthquakes
}

\author{
Seolhyang Baek', Seungwoo Han² \\ 'Department of Nursing, College of Nursing, Dongguk University, Gyeongju, Korea \\ ${ }^{2}$ Department of Emergency Medical Technology, College of Smart Life, Kyungil University, Gyeongsan, Korea
}

Objective This study aimed to investigate the factors influencing the emergency medical competency (EMC), perceived by the fire station and health center staff, in the areas where of emergency medical vulnerability where earthquakes had occurred.

Methods This study was conducted between December 2019 and February 2020. A proper questionnaire was created to evaluate EMC in disaster situations and administered to the fire station and the health center groups. Descriptive variables of each group were calculated. The Kendall rank correlation analysis was used to measure the relationships between the demographic variables, disaster-related variables, and EMC. The factors influencing the EMC for both groups were investigated in the linear regression analysis.

Results For a total of 200 respondents, the mean scores of EMC were $99.85 \pm 21.24$ and $95.24 \pm$ 20.05 for the fire station $(n=96)$ and the health center $(n=104)$ groups, respectively $(P=0.121)$. EMC was significantly correlated with age, years of service, job position, natural disaster experience, disaster relief service experience, and joint disaster response exercise $(P<0.050)$. Linear regression analysis revealed that the duration of joint disaster response exercise $(\beta=0.640, t=11.696)$ in Model $1(F=136.806, P<0.001)$, the duration of joint disaster response exercise $(\beta=0.627$, $P<0.001)$, and disaster rescue service experience $(\beta=0.124, P<0.001)$ in Model $2(F=72.431$, $P<0.001)$ were independently associated with EMC improvement.

Conclusion Our findings indicate that the disaster preparedness program with a longer duration of joint disaster response exercise and more frequent disaster rescue service experience is necessary for improved and systematic response to a disaster.

Keywords Firefighters; Disaster medicine; Emergency responders; Earthquakes; Community health centers

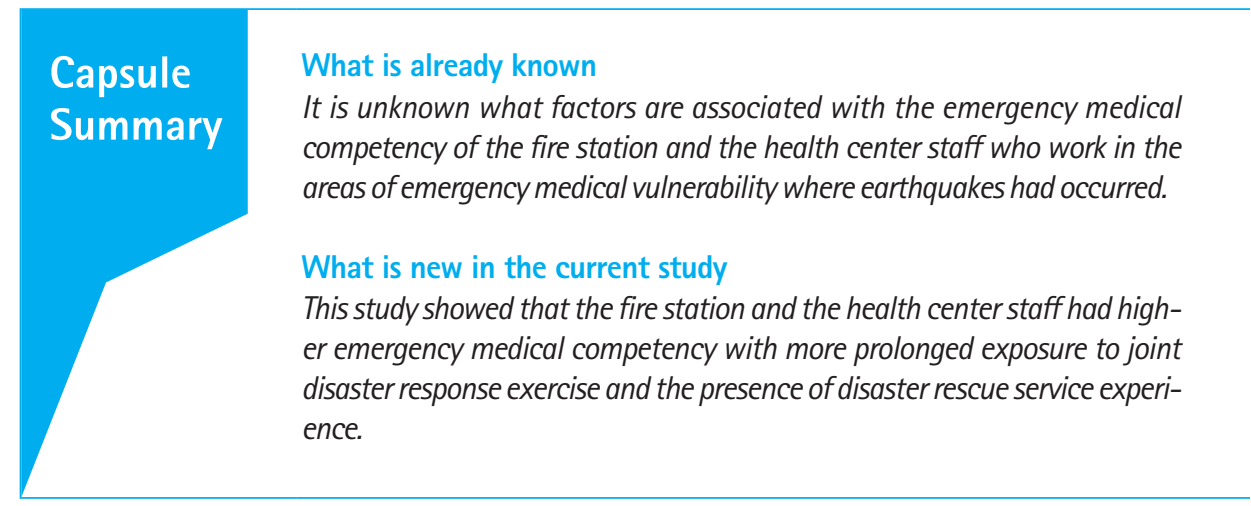

elSSN: 2383-4625

Received: 10 October 2020

Revised: 5 January 2021

Accepted: 16 February 2021

Correspondence to: Seungwoo Han Department of Emergency Medical Technology, College of Smart Life, Kyungil University, 50 Gamasil-gil, Hayang-eup, Gyeongsan 38428, Korea E-mail:swhan@kiu.ac.kr ORCID

https://orcid.org/0000-0001-9144-3285

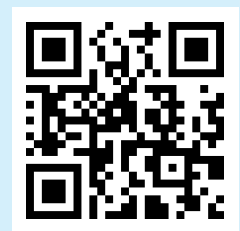

How to cite this article: Baek S, Han S. Factors influencing emergency medical competencies of health centers and fire stations in areas that are vulnerable to earthquakes. Clin Exp Emerg Med 2021;8(3):192-200. https://doi. org/10.15441/ceem.20.138

This is an Open Access article distributed under the terms of the Creative Commons Attribution Non-Commercial License (https:// creativecommons.org/licenses/by-nc/4.0/). 


\section{INTRODUCTION}

South Korea has recently been exposed to various disasters, especially natural causes, such as heatwaves and floods. The experience of and exposure to earthquakes, however, is rare. The recent earthquake in Pohang, South Korea, measured 5.4 on the Richter scale. According to the Korea Meteorological Administration, this was the second largest earthquake in South Korea, following a 5.8 magnitude earthquake in Gyeongju in September 2016. ${ }^{1}$ Since then, the government research team has investigated the cause of the Pohang earthquake, arguing for higher safety preparedness by citizens and stressing the need to strengthen capacity for proper education and higher competencies of medical use and awareness. $^{2}$

Competence refers to training and capabilities that affect the performance of a task, which assesses the expertise and specificity of the recognition and performance capabilities that are associated with increased interest in disaster emergency care. ${ }^{3}$ This study seeks to correlate the demographic variables of fire stations and health centers with emergency medical competency (EMC) and to identify the factors that affecting EMC. Identifying the factors affecting EMC at fire stations and health centers in the emergency medical vulnerable areas will also help establish a practical approach to the emergency medical situation in vulnerable areas and contribute to improve medical equity.

The emergency medical capacity of an institution plays a pivotal role in emergency medical care during disasters by securing the safety of people and helping save lives. The preparation, systematic management, and operations are very important at the country level. However, the accessibility of emergency medical facilities in South Korea varies greatly from one region to the other. An example is that of rural areas, where emergency medical services are scarce. In fact, a previous study found differences in healthcare within rural areas as well. ${ }^{4}$ In South Korea, local public health centers and fire stations play an essential role; the demographic characteristics of the population imply that the elderly are usually unable to use medical facilities because of their limited movement. ${ }^{5}$ In emergencies such as disasters, these facilities can play an essential role in ensuring primary emergency medical care reaches such people. South Korea seems to lack the legal and institutional basis for the evaluation and operational management of disaster medical support systems, resulting in weak management by local communities, cities, and the authorities responding to disasters. This deficiency hinders efficient response to disasters and amplifies conflict amongst agencies, which makes it difficult to provide cooperative and coordinated disaster medical support. ${ }^{6}$ To improve these problems and supplement the current emergency medical system, an evaluation of the roles and competencies of public institutions such as fire stations and health centers is urgently required. In this study, we intend to provide basic data on the establishment of crisis response and training programs for future disasters by identifying the factors affecting $\mathrm{EMC}$ in fire stations and health centers.

\section{METHODS}

\section{Study design}

This study is a descriptive investigative study that seeks to determine the extent of EMC in fire stations and health centers and to identify the factors that affect EMC.

\section{Study setting}

The subjects of this study were fire station and public health center officials working in areas vulnerable to emergency medical treatment in the Gyeongsangbuk-do province of South Korea, where an earthquake had occurred, and those who officially registered and worked for more than three months. From this group, those who agreed to participate in the study were randomly selected. The size of this study sample was calculated using the $\mathrm{G}^{*}$ Power 3.1.9 program, with significance level $a=0.05$, effect size 0.80 , power $1-\beta=0.80$; at least 130 samples were required for an independent one-sided t-test. ${ }^{7}$ A total of 210 questionnaires were distributed in consideration of the drop-out rate based on the standards listed above, and the final 200 questionnaires were analyzed. Ten questionnaires were excluded because of insufficient or missing information.

\section{Variables and measurements}

The researchers confirmed that there were no standardized tools to measure the disaster competencies of fire station and health center personnel who were the most active in the event of a disaster. Therefore, 30 questions were derived from the analysis of the 2019 Education and Training Plan (issued by the Ministry of Publication and Registration Advocate 11-1741053-000001-10), which was recently extracted from the 'field disaster medical response handbook.' Since then, face validity has been verified by a panel of ten earthquake disaster experts, including emergency medical specialists, internal medicine specialists, and middle management executives of fire stations and health centers.

Consequently, a total of 33 questions (Appendix 1), consisting of a 5-point Likert scale, were completed. When the completed questions were re-examined, the rotated factor matrix was obtained with three factors, and overall factor reliability was measured at 0.798 . 
The total score of the questionnaire ranges from a minimum of 33 to a maximum of 165 points; a higher score implies a higher EMC.

\section{Data collection}

This study was conducted after receiving approval from the institutional review board of Kyungil University (KIU-1041459-201911HR-019-01) and was conducted from December 15, 2019 to February 28,2020 . Prior to the study, a researcher explained the purpose and method of the study, while the suitability of the questionnaire was verified through an executive meeting and permission and cooperation were obtained for conducting the study. A researcher visited eight organizations in each of the fire stations and public health centers within the emergency medical vulnerable areas, where the earthquake had occurred, and gave a questionnaire to the participants with an explanation of the purpose of the study and the questionnaire response method. The researcher explained that the survey results would be numerically processed and would not be used for any other purposes. The researcher obtained written informed consent for voluntary participation after explaining the purpose, anonymity, and confidentiality of the study to the participants. The questionnaire was answered and sealed in an envelope provided. The time given for the survey was about 10 minutes, and we explained that the subject could stop at any time without a disadvantage and could exercise the right to access and modify the data at any time with the researcher according to the law. Souvenirs were provided to subjects who filled in the questionnaire.

\section{Statistical analysis}

In this study, the collected data were processed using the SPSS Statistics ver. 17.0 (SPSS Inc., Chicago, IL, USA). The general characteristics of health centers and fire stations were calculated for absolute numbers, percentages, chi-square test, and P-value. EMC levels at health centers and fire stations were analyzed for average, standard deviation, t-test, and P-value. The correlation between demographic variables and EMC was measured using Kendall rank correlation analysis. Linear regression (stepwise procedure) was applied to determine the impact of the two groups on EMC. A scatter diagram was formulated to clarify the relationship between joint exercises on disaster response and EMC.

\section{RESULTS}

\section{Demographic and disaster related characteristics of fire station and health center workers}

Table 1 shows basic characteristics of 200 participants, focusing on their institutions. Among men, 88 (81.5\%) worked at the fire station, while 76 women (83.5\%) worked at the health center, showing significant gender differences in workplace locations $\left(\chi^{2}=84.520, P<0.001\right)$. Their average age (standard deviation) was 39.34 (9.65) for those working at fire stations and 43.04 (10.24) at health centers, indicating that health workers were relatively older $(t=-2.634, P=0.009)$. The average years of service (standard deviation) of the study participants was 13.18 (9.33) for those working at the fire station and 16.94 (11.24) for those working at the health centers, showing differences among groups $(t=-2.579$, $P=0.011)$. In of academic background of the participants, 101 respondents were university graduates, which further showed significant differences among groups $(\mathrm{t}=10.111, \mathrm{P}=0.018)$.

The highest number of positions in the workplace was at 8th to 9th grade $(n=93) ;$ In the job position of fire stations and health centers, grade 8 and 9 accounted for the largest percentage $(n=93) ; 47$ contract workers in the fire station, and 68 in the health center, respectively $\left(\chi^{2}=54.071, P<0.001\right)$.

There were 129 cases of people working for the headquarters, which was the most frequent. There were 66 people working in the fire station branch offices, while there were 91 people working in the health center headquarters, showing significant differences among groups $\left(\chi^{2}=73.982, \mathrm{P}<0.001\right)$. A comparison of licenses or certificates held by research participants showed that 52 respondents were found to have nurses' licenses, 29 were emergency medical technicians, 10 were lifeguards, 21 were firefighting equipment engineers, and 42 had fire response capabilities. Nurses mostly worked at health centers, while other certified workers were found to be members of the fire station. The average number of certificates (standard deviation) of fire department workers was 1.05 (7.74) and of health center workers was 0.41 (0.52), indicating differences among groups $(t=7.547, P<0.001)$. Most of the organizations were located in towns $(n=116)$; fire stations had 70 employees in towns, while health centers had 48 employees in the county $\left(\chi^{2}=66.737, P<0.001\right)$. According to the survey on whether a disaster had been experienced in real life, 166 people said that they had experienced it in real life and accounted for the majority, but the difference between groups was not measured. On the questions asking about the rescue service experience during real disasters, 189 people said that they did not have any such experience, and only six participants from fire stations and five ones in health centers responded that they had experienced such a situation. No group differences were found. In the past year, the average duration of joint exercises on disaster response (standard deviation) was 4.52 hours (4.95) at fire stations and 3.24 hours (5.98) at health centers, and there was no difference between groups. 
Table 1. Demographic and disaster-related variables of study participants $(n=200)$

\begin{tabular}{|c|c|c|c|c|c|}
\hline Category & & Fire station $(n=104)$ & Health center $(n=96)$ & $\chi^{2} / \mathrm{t}$ & P-value \\
\hline \multirow[t]{2}{*}{ Sex } & Male $(n=108)$ & $88(81.5)$ & $20(18.5)$ & 84.520 & $<0.001$ \\
\hline & Female $(n=91)$ & $15(16.5)$ & $76(83.5)$ & & \\
\hline Age $(y r)$ & & $39.34 \pm 9.65$ & $43.04 \pm 10.24$ & -2.634 & 0.009 \\
\hline Years of service (yr) & & $13.18 \pm 9.33$ & $16.94 \pm 11.24$ & -2.579 & 0.011 \\
\hline \multirow[t]{4}{*}{ Education } & High school $(n=14)$ & $11(78.6)$ & $3(21.4)$ & 10.111 & 0.018 \\
\hline & College $(n=74)$ & 31 (41.9) & $43(58.1)$ & & \\
\hline & University $(n=101)$ & $58(57.4)$ & $43(42.6)$ & & \\
\hline & Graduate school $(n=10)$ & $3(30.0)$ & 7 (70.0) & & \\
\hline \multirow[t]{4}{*}{ Job position (grade) } & Contract $(n=53)$ & 47 (88.7) & $6(11.3)$ & 54.071 & $<0.001$ \\
\hline & 8th to 9 th $(n=93)$ & 25 (26.9) & $68(73.1)$ & & \\
\hline & 6th to 7 th $(n=51)$ & $31(60.8)$ & $20(39.2)$ & & \\
\hline & 4th to 5 th $(n=3)$ & $1(33.3)$ & $2(66.7)$ & & \\
\hline \multirow[t]{2}{*}{ Service agency } & Headquarters $(n=129)$ & 38 (29.5) & $91(70.5)$ & 73.982 & $<0.001$ \\
\hline & Branch $(n=71)$ & 66 (93.0) & $5(7.0)$ & & \\
\hline \multirow[t]{6}{*}{ License/certificate ${ }^{a)}$} & Nurse $(n=52)$ & $15(28.8)$ & $37(71.2)$ & 15.093 & $<0.001$ \\
\hline & Emergency medical technician $(n=29)$ & $27(93.1)$ & $2(6.9)$ & 22.959 & $<0.001$ \\
\hline & Lifesaving $(n=10)$ & $10(100.0)$ & $0(0.0)$ & 9.717 & 0.002 \\
\hline & Engineer fire protection $(n=21)$ & $20(19.2)$ & $1(1.0)$ & 17.575 & $<0.001$ \\
\hline & Fire response capability $(n=42)$ & $41(97.6)$ & $1(2.4)$ & 44.327 & $<0.001$ \\
\hline & Total number of license/certificate & $1.05 \pm 0.74$ & $0.41 \pm 0.52$ & 7.547 & $<0.001$ \\
\hline \multirow[t]{3}{*}{ Agency Location } & Metropolitan city $(n=30)$ & $29(96.7)$ & $1(3.3)$ & 66.737 & $<0.001$ \\
\hline & Town $(n=116)$ & $70(60.3)$ & 46 (39.7) & & \\
\hline & County $(n=54)$ & $5(9.3)$ & $48(90.7)$ & & \\
\hline \multirow[t]{2}{*}{ Experience in natural disaster } & Yes $(n=166)$ & $87(52.4)$ & $79(47.6)$ & 0.066 & 0.798 \\
\hline & No $(n=34)$ & $17(50.0)$ & $17(50.0)$ & & \\
\hline \multirow{2}{*}{$\begin{array}{l}\text { Rescue service experience } \\
\text { in disaster }\end{array}$} & Yes $(n=11)$ & $6(54.5)$ & $5(45.5)$ & 0.030 & 0.862 \\
\hline & No $(n=189)$ & $98(51.9)$ & $91(48.1)$ & & \\
\hline $\begin{array}{l}\text { Joint exercise on disaster } \\
\text { response last year (hr) }\end{array}$ & & $4.52 \pm 4.95$ & $3.24 \pm 5.98$ & & 0.100 \\
\hline
\end{tabular}

Values are presented as number (\%) or mean \pm standard deviation.

${ }^{a}$ Multiple answer was allowed.

To sum up these results, participants in fire departments and health centers showed a significant difference in demographic characteristics, including gender, age, education, position, license or certification, and agency location. Disaster related experiences, however, showed homogeneity.

\section{Comparison of the EMC between fire station and health center professionals}

The result of measuring the EMC between fire station and health center workers was that the average EMC for fire stations (standard deviation) was 99.85 points (21.24) and for health centers was 95.24 points (20.50), with no statistical differences found between groups (Table 2).

\section{Correlation of demographic, disaster related variables,} and EMC within the study participants

The results of an analysis of the correlation between demographic and disaster related variables and EMC are as follows (Table 3). First, the affiliation has shown significant correlation with sex, age, years of service, position, agency location, and duration of joint exercises on disaster response $(\mathrm{P}<0.050)$. Sex showed significant correlation with workplace size, number of licenses or certificates, agency location, duration of joint exercises on disaster response, etc. $(\mathrm{P}<0.010)$. Age showed the highest correlation with years of service $(\tau=0.849, P<0.001)$. It was also significantly related to most variables, such as position and workplace size. The years of service were also significantly related to most variables, including the workplace size, the number of licenses or certificates, and the workplace location. Education showed the only significant correlation with the duration of joint exercises on disaster response ( $\tau=0.126, P=0.037)$. The position showed significant correlation with four variables: workplace location, experience of natural disaster, rescue service experience in disasters, and EMC $(P<0.050)$. The number of licenses and certificates showed 
a weak correlation with the duration of joint exercises on disaster response $(\tau=0.123, P=0.044)$. Experience of natural disasters showed a weak correlation between duration of joint exercises on disaster response $(\tau=0.142, P<0.001)$ and EMC $(\tau=0.125$, $P=0.033)$. Rescue service experience during disasters also showed a weak correlation with EMC ( $\tau=0.149, P=0.011)$. The duration of joint exercises on disaster response showed a significant intermediate degree of correlation with EMC $(\tau=0.501, P<0.001)$.

To summarize these results, the duration of joint exercises on disaster response of the participants in this study showed a weak correlation with their affiliation, sex, age, years of service, education, license or qualification, and experience of natural disasters. EMC showed weak correlations with age, years of service, posi-

Table 2. Comparison of EMC between fire station and health center professionals $(n=200)$

\begin{tabular}{lccc}
\hline Group & EMC $($ score $)$ & $t$ & P-value \\
\hline Fire station $(n=104)$ & $99.85 \pm 21.24$ & 1.558 & 0.121 \\
Health center $(n=96)$ & $95.24 \pm 20.50$ & & \\
\hline
\end{tabular}

Values are presented as mean \pm standard deviation.

EMC, emergency medical competency. tion, experience of natural disasters, rescue service experience during disasters, etc. It also showed a medium correlation with the duration of joint exercises on disaster response. Therefore, the researchers constructed a scatter diagram, focusing on the relevance between the duration of joint exercises on disaster response and EMC. The majority of participants had less than 0 to 5 hours of training experience, and their EMC scores were also concentrated to less than 120 points (Fig. 1).

\section{Factors affecting the EMC in fire station and health center professionals}

The researchers applied linear regression with stepwise selection to identify factors affecting EMC (Table 4). Model 1 shows that EMC improves by 0.64 as the duration of joint exercises on disaster response increases by 1 hour $(\beta=0.640$ ). This equation had an explanatory power of about $40.7 \%$ (adjusted $R$ square $=0.407$, $\mathrm{P}<0.001)$. Model 2 included the duration of joint exercises on disaster response and rescue service experience in disasters as factors affecting $\operatorname{EMC}(\beta=0.627, \beta=0.124$, respectively). These variables had an explanatory power of $41.9 \%$ for EMC (adjusted $\mathrm{R}$ square $=0.419, \mathrm{P}<0.001)$.

Table 3. Correlation of the participants' demographic variables and EMC score $(n=200)$

\begin{tabular}{|c|c|c|c|c|c|c|c|c|c|c|c|c|c|}
\hline & (1) & (2) & (3) & (4) & (5) & (6) & (7) & (8) & (9) & (10) & (11) & (12) & (13) \\
\hline \multicolumn{14}{|l|}{ (1) Affiliation } \\
\hline (2) $\operatorname{Sex}$ & $\begin{array}{l}-0.648^{* * *} \\
(<0.001)\end{array}$ & & & & & & & & & & & & \\
\hline (3) Age & $\begin{array}{c}0.153^{*} \\
(0.010)\end{array}$ & $\begin{array}{l}-0.022 \\
(0.704)\end{array}$ & & & & & & & & & & & \\
\hline (4) Years of service & $\begin{array}{l}0.155^{* *} \\
(0.009)\end{array}$ & $\begin{array}{l}-0.048 \\
(0.419)\end{array}$ & $\begin{aligned} & 0.849^{* * *} \\
&(<0.001)\end{aligned}$ & & & & & & & & & & \\
\hline (5) Education & $\begin{array}{l}-0.005 \\
(0.947)\end{array}$ & $\begin{array}{l}-0.095 \\
(0.160)\end{array}$ & $\begin{array}{c}0.024 \\
(0.668)\end{array}$ & $\begin{array}{l}-0.036 \\
(0.522)\end{array}$ & & & & & & & & & \\
\hline (6) Job position (grade) & $\begin{array}{l}0.203^{* *} \\
(0.002)\end{array}$ & $\begin{array}{c}-0.089 \\
(0.181)\end{array}$ & $\begin{aligned} & 0.548^{* * *} \\
&(<0.001)\end{aligned}$ & $\begin{array}{l}{ }^{*} 0.522^{* * *} \\
(<0.001)\end{array}$ & $\begin{array}{c}0.048 \\
(0.455)\end{array}$ & & & & & & & & \\
\hline (7) Service agency & $\begin{aligned} & 0.608^{* * *} \\
&(<0.001)\end{aligned}$ & $\begin{array}{l}-0.450^{* * *} \\
(<0.001)\end{array}$ & $\begin{array}{c}0.204^{* *} \\
(0.001)\end{array}$ & $\begin{array}{c}0.177^{* *} \\
(0.003)\end{array}$ & $\begin{array}{c}0.086 \\
(0.204)\end{array}$ & $\begin{aligned} & 0.358^{* * *} \\
&(<0.001)\end{aligned}$ & & & & & & & \\
\hline $\begin{array}{l}\text { (8) License/certificate } \\
\text { (number) }\end{array}$ & $\begin{array}{l}-0.449^{* * *} \\
(<0.001)\end{array}$ & $\begin{array}{c}0.228^{* *} \\
(0.001)\end{array}$ & $\begin{array}{l}-0.123^{*} \\
(0.030)\end{array}$ & $\begin{array}{l}-0.130^{*} \\
(0.022)\end{array}$ & $\begin{array}{c}0.105 \\
(0.109)\end{array}$ & $\begin{array}{l}-0.087 \\
(0.177)\end{array}$ & $\begin{array}{l}-0.319^{* * *} \\
(<0.001)\end{array}$ & & & & & & \\
\hline (9) Agency location & $\begin{aligned} & 0.552^{* * *} \\
&(<0.001)\end{aligned}$ & $\begin{array}{l}-0.331^{* * *} \\
(<0.001)\end{array}$ & $\begin{array}{c}0.114^{*} \\
(0.044)\end{array}$ & $\begin{array}{c}0.134^{*} \\
(0.018)\end{array}$ & $\begin{array}{l}-0.094 \\
(0.147)\end{array}$ & $\begin{array}{r}0.140^{*} \\
(0.029)\end{array}$ & $\begin{aligned} & 0.353^{* * *} \\
&(<0.001)\end{aligned}$ & $\begin{array}{l}-0.271^{* * *} \\
(<0.001)\end{array}$ & & & & & \\
\hline $\begin{array}{l}\text { (10) Experience in natural } \\
\text { disaster }\end{array}$ & $\begin{array}{c}-0.018 \\
(0.798)\end{array}$ & $\begin{array}{l}-0.116 \\
(0.102)\end{array}$ & $\begin{array}{r}0.124^{*} \\
(0.035)\end{array}$ & $\begin{array}{c}0.133^{*} \\
(0.024)\end{array}$ & $\begin{array}{c}0.037 \\
(0.587)\end{array}$ & $\begin{array}{l}0.193^{* *} \\
(0.004)\end{array}$ & $\begin{array}{c}0.082 \\
(0.250)\end{array}$ & $\begin{array}{c}0.033 \\
(0.633)\end{array}$ & $\begin{array}{l}-0.031 \\
(0.646)\end{array}$ & & & & \\
\hline $\begin{array}{l}\text { (11) Rescue service experi- } \\
\text { ence in disaster }\end{array}$ & $\begin{array}{l}-0.012 \\
(0.862)\end{array}$ & $\begin{array}{l}-0.088 \\
(0.212)\end{array}$ & $\begin{array}{l}0.195^{* *} \\
(0.001)\end{array}$ & $\begin{array}{l}0.185^{* *} \\
(0.002)\end{array}$ & $\begin{array}{c}0.094 \\
(0.164)\end{array}$ & $\begin{array}{l}0.175^{* *} \\
(0.009)\end{array}$ & $\begin{array}{l}-0.096 \\
(0.176)\end{array}$ & $\begin{array}{c}0.007 \\
(0.924)\end{array}$ & $\begin{array}{c}0.924 \\
(0.123)\end{array}$ & $\begin{array}{c}0.109 \\
(0.124)\end{array}$ & & & \\
\hline $\begin{array}{l}\text { (12) Joint exercise on } \\
\text { disaster response (hr) }\end{array}$ & $\begin{array}{l}-0.182^{* *} \\
(0.004)\end{array}$ & $\begin{array}{l}0.171^{* *} \\
(0.007)\end{array}$ & $\begin{array}{l}0.149^{* *} \\
(0.005)\end{array}$ & $\begin{array}{c}0.132^{*} \\
(0.012)\end{array}$ & $\begin{array}{r}0.126^{*} \\
(0.037)\end{array}$ & $\begin{aligned} & 0.277^{* * *} \\
&(<0.001)\end{aligned}$ & $\begin{array}{l}-0.063 \\
(0.320)\end{array}$ & $\begin{array}{r}0.123^{*} \\
(0.044)\end{array}$ & $\begin{array}{l}0.0 .028 \\
(0.644)\end{array}$ & $\begin{array}{r}0.142^{*} \\
(0.025)\end{array}$ & $\begin{array}{c}0.092 \\
(0.146)\end{array}$ & & \\
\hline (13) EMC & $\begin{array}{l}-0.096 \\
(0.101)\end{array}$ & $\begin{array}{c}0.082 \\
(0.159)\end{array}$ & $\begin{array}{c}0.102^{*} \\
(0.036)\end{array}$ & $\begin{array}{c}0.097^{*} \\
(0.046)\end{array}$ & $\begin{array}{c}0.080 \\
(0.152)\end{array}$ & $\begin{array}{c}0.182^{* *} \\
(0.001)\end{array}$ & $\begin{array}{c}-0.002 \\
(0.979)\end{array}$ & $\begin{array}{c}0.095 \\
(0.092)\end{array}$ & $\begin{array}{c}0.026 \\
(0.647)\end{array}$ & $\begin{array}{c}0.125^{*} \\
(0.033)\end{array}$ & $\begin{array}{c}0.149^{*} \\
(0.011)\end{array}$ & $\begin{array}{c}0.501^{* * *} \\
(<0.001)\end{array}$ & \\
\hline
\end{tabular}

Kendall rank correlation analysis was applied. Data shown are Kendall correlation coefficient $\mathrm{T}$ (P-value). ${ }^{*} \mathrm{P}<0.010,{ }^{* *} \mathrm{P}<0.001,{ }^{* * *} \mathrm{P}<0.001$.

EMC, emergency medical competency. 
Table 4. Factors affecting the emergency medical competency in fire station and health center professionals $(n=200)$

\begin{tabular}{|c|c|c|c|c|c|c|c|c|}
\hline \multirow{2}{*}{ Model } & \multirow{2}{*}{ Variable } & \multicolumn{2}{|c|}{ Non-standardized coefficient } & \multicolumn{2}{|c|}{ Standardized coefficient } & \multirow{2}{*}{$\begin{array}{c}\text { Adjusted } \\
\mathrm{R}^{2}\end{array}$} & \multirow{2}{*}{$\mathrm{F}$} & \multirow{2}{*}{ P-value } \\
\hline & & B & SE & $\beta$ & $\mathrm{t}$ & & & \\
\hline \multirow[t]{2}{*}{1} & (Constant) & 87.982 & 1.409 & - & 62.430 & 0.407 & 136.806 & $<0.001$ \\
\hline & Joint exercise on disaster response (hr) & 2.444 & 0.209 & 0.640 & 11.696 & & & \\
\hline \multirow[t]{3}{*}{2} & (Constant) & 87.547 & 1.408 & - & 62.192 & 0.419 & 72.431 & $<0.001$ \\
\hline & Joint exercise on disaster response (hr) & 2.395 & 0.208 & 0.627 & 11.521 & & & \\
\hline & Rescue service experience in disaster & 11.339 & 4.990 & 0.124 & 2.272 & & & \\
\hline
\end{tabular}

a) Stepwise linear regression.

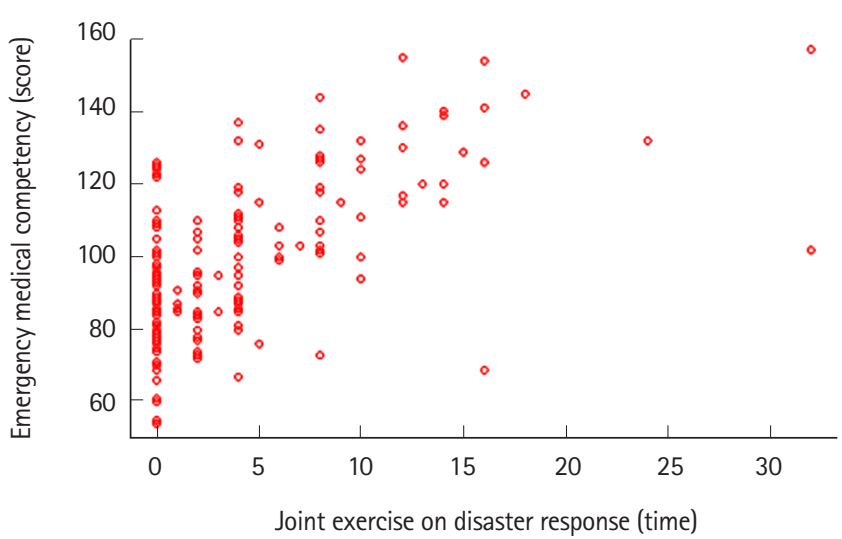

Fig. 1. Relation of joint exercise on disaster response and emergency medical competency score.

\section{DISCUSSION}

This study aimed to investigate the factors affecting EMC at fire station and health center professionals in the emergency medical vulnerable areas of Gyeongsangbuk-do where earthquakes had occurred. This study discusses how the current emergency medical system should be appropriately supplemented to help in the improvement of the roles and competencies of public institutions such as fire stations and health centers.

Participants in fire departments and health centers showed a significant difference in demographic characteristics, including sex, age, education, position, license or certificate, and agency location. However, the duration of joint exercises on disaster response, rescue service experience during actual disasters, and experience of real natural disasters showed homogeneity in results. These results exposed many limitations in terms of the duration of joint exercises on disaster response, rescue service experience during disasters, and experience of natural disasters. Previous studies ${ }^{9}$ have shown how public health centers in South Korea have established emergency medical centers, have transferred patients, have carried out emergency response trainings for many casualties, and comprehensive emergency rescue drills once a year. These trainings were not unified across the country, indicating that there were many limitations in improving disaster preparedness.

Meanwhile, in another study of firefighters, ${ }^{10}$ demographic variables such as age, career, and qualification showed statistically significant differences in patient treatment and patient triage competency. However, other aspects, such as collaborative support competencies, have not produced statistically significant results for any demographic variables.

Based on these results, developing practical response competencies such as joint exercises on disaster response, rescue service experience of disaster, and experience of having lived through a natural disaster could be an important factor in improving the practical competency of fire station and health center personnel in the event of a disaster. Another previous study ${ }^{11}$ also presented disaster experiences as factors affecting disaster core competencies. In order to improve the EMC of fire station and health center workers, the researchers believe that joint training of fire stations and health centers should be continuously accompanied by various development programs that are related to disaster situations.

Although it is not the same tool as the one discussed in a previous study, ${ }_{1}^{12}$ the disaster response competency showed statistically significant differences in work experience, disaster preparedness, etc. EMC is considered to be closely related to practical experience and will need to be accompanied by appropriate competency improvement training during the job performance process.

In this study, fire stations and health centers had less than 0 to 5 hours of training per year, but specifically, the combined training time for one year was 4.52 and 3.24 hours, respectively. This is insufficient, especially compared to disaster response standards of other countries. This requires joint emergency response trainings between the central government and agencies, but it is difficult for interministerial cooperation to take place. ${ }^{13}$ Recently, various disaster response trainings have been held in South Korea, and joint trainings are conducted mainly by police officers, firefighters, military, and medical institutions to minimize damage in the event of a disaster. Joint trainings should be accompanied by consistent and systematic disaster response training and educa- 
tion to enhance the specialty and efficiency of emergency medical competencies. Currently, education that is relevant to this topic in South Korea's disaster response consists mainly of duty, professional development, and knowledge and plays an important role in enhancing the specialty and efficiency of education in public institutions such as fire stations and health centers. Therefore, it will be necessary to establish disaster response procedures, protocol development, and disaster management systems that can adapt to the situation in South Korea, focusing on fire stations and health centers.

Finally, linear regression with stepwise selection was applied to identify factors that affect EMC. For the fire station and health center workers, it was found that EMC improved as the duration of joint exercises on disaster response and rescue service experience in actual disasters increased.

These results are consistent with prior research findings ${ }^{14}$ that rescue service experience in actual disasters affects core performance during subsequent disasters. In another study, ${ }^{15}$ those who have experienced rescue service during disasters tend to be more resilient during crisis situations than those who have not experienced such situations, and the former also tend to make social connectivity easier. Therefore, rescue service experience during actual disasters can improve the capability of fire station and health center workers. It will also be important to establish a disaster response management system by implementing disaster prevention, response, and training plans and evaluation. However, only six individuals from fire stations and five from health centers in this study had experienced rescue service in real disasters. Based on these findings, the researchers believe that Korean fire stations and health centers will desperately need educational programs to develop their ability to respond more systematically to disasters in the future.

This also suggests that systematic response education and joint training among ministries should be established to enhance the disaster management expertise of public institutions.

The results of this study also show that EMC increases as the duration of joint exercises on disaster response increases. These findings are consistent with previous research, ${ }^{16}$ indicating that the more joint trainings linked to fire stations and health centers are conducted, the better the ability to prepare in advance and respond quickly on site. In addition, many joint trainings can enhance on-site response capabilities by establishing a crisis response system among related agencies in the community. These can minimize casualties in the event of a disaster and can promote safety awareness among residents. However, similar to the results of this study, the number of employees who receive joint training in one year was only 3 to 10 and very few were participating in the joint training to begin with. ${ }^{16}$ Even within cities, joint trainings between fire stations and health centers are conducted only twice a year. This suggests the need to increase regular joint training in the future. Fire stations and health centers will need more practical and diverse training through the development of joint training programs and special situation disaster programs.

There were two limitations in this study. First, this study was just conducted for the limiting medically vulnerable areas to the disaster prone Gyeongsangbuk-do, where the most recent earthquake in South Korea occurred; further research will need to be conducted by expanding to other areas such as the disaster safe city of Busan and the special disaster zone of Ansan. Second, this study focused on fire stations and health centers carrying out emergency medical systems during disasters. In future studies, it is important to evaluate the competencies of other groups that also play a pivotal role during a disaster, such as police stations and the military.

In conclusion, the disaster preparedness program, including the longer the duration of joint exercises on disaster response and the more rescue service experience in a disaster will be needed to respond more systematically to a disaster.

\section{CONFLICT OF INTEREST}

No potential conflict of interest relevant to this article was reported.

\section{ACKNOWLEDGMENTS}

We thank the fire stations and health centers for responding to the survey.

\section{REFERENCES}

1. Park ES, Yoon DK, Choi YW. Leave no one behind: experiences of persons with disability after the 2017 Pohang earthquake in South Korea. Int J Disaster Risk Reduct 2019;40:101261.

2. Ha KM. How a moderate earthquake has improved earthquake awareness in Korea. Int J Environ Res 2018;12:955-64.

3. Kim Y, Yeom S, Jeon Y, et al. Public Health Disaster Response Team's awareness on disaster medical management capacity. J Korean Soc Emerg Med 2020;31:88-98.

4. Buzza $C_{1}$ Ono SS, Turvey $C_{1}$ et al. Distance is relative: unpacking a principal barrier in rural healthcare. J Gen Intern Med 2011;26 Suppl 2(Suppl 2):648-54.

5. Choi Y, Nam K, Kim CY. Association between convenience of transportation and unmet healthcare needs of rural elderly in 
Korea. J Prev Med Public Health 2019;52:355-65.

6. Wang SJ. Designing the national disaster medical management system and developing the standard manual for disaster medical management. Sejong: Ministry of Health and Welfare; 2012.

7. Faul F, Erdfelder E, Buchner A, Lang AG. Statistical power analyses using $G^{*}$ Power 3.1: tests for correlation and regression analyses. Behav Res Methods 2009;41:1149-60.

8. Central Emergency Medical Center; Gyeongbuk Emergency Medical Assistant Center. Handbook: field medical assistant response in disaster. Gyeongju: Gyeongbuk Emergency Medical Supporting Center; 2019.

9. Lee YR, Lee MH. A study on disaster preparedness competency in public health center workers. J Korean Acad Soc Nurs Educ 2016;22:96-109.

10. Lee $J H$, Lee $K Y$. Study on disaster response competencies of 119 EMTs. Korean J Emerg Med Serv 2018;22:55-66.
11. Park HY, Kim JS. Factors influencing disaster nursing core competencies of emergency nurses. Appl Nurs Res 2017;37:1-5.

12. Park JC, Lee KY. Disaster preparedness and response competency of emergency medical technician-paramedics in the disaster medical assistant team. Korean J Emerg Med Serv 2019; 23:19-31.

13. Kim GH, Sung DK. A study on the effective operation of disaster management plan: focused on the cases of the United States and Japan. Korean Public Adm 0 2011;23:121-44.

14. Park HY. Factors influencing the disaster nursing core competencies of emergency room nurses [thesis]. Incheon: Gachon University; 2015.

15. Boon HJ. Disaster resilience in a flood-impacted rural Australian town. Nat Hazards 2014;71:683-701.

16. Cho YH, Chung Y, Chie N. Status and issues on disaster preparation programs in public health center. J Agric Med Community Health 2018;43:63-73. 
Appendix 1. Questionnaire for emergency medical competency assessment

Please select the number below that best represents you feel about your emergency medical competency for earthquake response.

\begin{tabular}{|c|c|c|c|c|c|c|}
\hline \multirow{2}{*}{ No. } & \multirow{2}{*}{ Item } & \multicolumn{5}{|c|}{ Answer ${ }^{a)}$} \\
\hline & & 5 & 4 & 3 & 2 & 1 \\
\hline
\end{tabular}

I can...

1 define key concepts, causes, hazard areas of earthquake.

2 understand concepts of disaster management, basic laws and principles related to disaster and safety management.

3 describe earthquake hazard areas in community.

4 understand the national disaster management system based on disaster environmental changes.

5 understand emergency communication system, concepts and countermeasures in terms of disaster management.

6 understand and apply the manuals for natural disaster response.

7 enumerate earthquake countermeasures and damage recovery tips.

8 be aware of importance of cooperation between disaster management departments

9 take part in national disaster response drill(s)

10 cultivate disaster response competency by participation of national disaster response drill(s)

11 be aware of step-by-step instructions for disaster management.

12 elicit problem(s) originated from a failure case of disaster response

13 cultivate its competency by learning a failure case of disaster response

14 explain disaster relief areas such as acts, policy, policy direction, operation of temporary shelter for victims.

15 put into words response tips to public opinion and press during a large-scale or complex disaster.

16 apply media communication tips during a large-scale or complex disaster.

17 manage emergency medical supplies and materials for disaster response.

18 identify damage type and cases of disaster victims and apply countermeasures for PTSD.

19 classify psychological first aids relevant to disaster type and stage requiring support for psychological recovery.

20 elicit medical response steps appropriate for on-site disaster.

21 explain dispatch system for on-site disaster.

22 enumerate quick response team and system of disaster medical support.

23 explain composition of on-site emergency medical center at disaster.

24 distinguish each one's(classification team, first aids team, transport team) roles of on-site emergency medical center at disaster.

25 describe missions and roles of paramedics(first-come etc.) at disaster.

26 describe missions and roles of on-site emergency medical center's director (community health center director) at disaster.

27 describe missions and roles of the quick response team of community health center at disaster.

28 explain principles and importance of documentation and operation assistance at disaster.

29 explain on-site communication (tools, contents, principles) at disaster.

30 define roles of central emergency medical center at disaster.

31 define missions and roles in a disaster relief area (e.g. field command post, field emergency medical center, relief center).

32 acknowledge stronghold hospital in our community.

33 identify disaster medical manager in our community.

a) 5, strongly agree; 4, agree; 3 , neither agree nor disagree; 2 , disagree; 1 , strongly disagree. 